\title{
Correction to: Post-earthquake response by small UAV helicopters
}

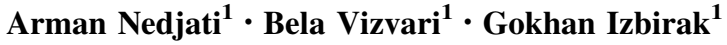

Published online: 15 November 2017

(C) Springer Science+Business Media B.V., part of Springer Nature 2017

\section{Correction to: Nat Hazards (2016) 80:1669-1688 https://doi.org/10.1007/s11069-015-2046-6}

The original publication has the following mistakes which we hereby correct:

- In Fig. 3 the "UAV routs" should be replaced by "UAV routes".

- On page 1685 the sentence in the main text after the equations currently reads: "In the model, Eq. (1) minimizes the total number of missions for all UAV helicopters" It should instead read:

"In the model, Eq. (1) minimizes the total flight time for all UAV helicopters"

The authors regret these errors and apologize for any inconvenience caused.

The original article can be found online at https://doi.org/10.1007/s11069-015-2046-6.

Arman Nedjati

arman.nedjati@gmail.com; arman.nedjati@cc.emu.edu.tr

Bela Vizvari

bela.vizvari@emu.edu.tr

Gokhan Izbirak

gokhan.izbirak@emu.edu.tr

1 Industrial Engineering Department, Eastern Mediterranean University, via Mersin 10, Famagusta, North Cyprus, Turkey 